\title{
Pelatihan Tata Hidangan bagi Masyarakat di Desa Kedonganan, Badung, Bali
}

\author{
Ni Kadek Eni Juniari* , Putu Mira Astuti Pranadewi², \\ Program Studi Manajemen Tata Hidangan, Politeknik Pariwisata Bali \\ Jl. Dharmawangsa, Kampial, Nusa Dua, Telp. (0361) 773537-38 \\ 1*enijuniari@ppb.ac.id, ${ }^{2}$ mira.pranadewi@gmail.com, \\ *Corresponding author
}

\begin{tabular}{c|c|c}
\hline Received: Mei, 2021 & Accepted: Mei, 2021 & Published: June, 2021 \\
\hline
\end{tabular}

\begin{abstract}
Kedonganan Village is famous as a culinary tourism village. Developments and increasingly fierce competition, the village considers it necessary to prepare human resources who can provide maximum service to tourists. In response to this, training is needed on excellent service, hygiene, sanitation and work safety as well as the manufacture of mixed drinks for the community. The purpose of this activity is to provide an overview of the field of hospitality and service excellence to the community in Kedonganan Village, to provide an understanding of hygiene, sanitation and work safety as well as basic knowledge of beverages to the community in Kedonganan Village, as well as to provide training on how to making and serving mixed drinks for the community in Kedonganan Village. The participants of the activity were a total of 60 people, consisting of representatives from 6 Banjars in Kedonganan Village. This activity is carried out with 3 (three) methods, namely in the form of lectures, discussions and direct practice. The results of this activity can be seen from the enthusiasm of the participants in participating from the first day to the end and the participants gave very positive responses to this activity. They hope that such activities can be carried out continuously with different materials.
\end{abstract}

Keywords: food and beverage service, excellent service, mixed drinks

\begin{abstract}
Abstrak
Desa Kedonganan terkenal sebagai desa wisata kuliner. Perkembangan dan persaingan yang semakin ketat maka pihak Desa memandang perlu untuk mempersiapkan sumber daya manusia yang dapat menyediakan pelayanan yang maksimal kepada wisatawan. Menyikapi hal tersebut, dibutuhkan adanya pelatihan mengenai pelayanan prima, hygiene, sanitasi dan keselamatan kerja serta pembuatan minuman campuran bagi masyarakat. Tujuan dari kegiatan ini adalah untuk memberikan gambaran umum mengenai bidang hospitaliti dan pelayanan prima (service excellent) kepada masyarakat di Desa Kedonganan, untuk memberikan pemahaman mengenai hygiene, sanitasi dan keselamatan kerja serta pengetahuan dasar minuman kepada masyarakat di Desa Kedonganan, serta untuk memberikan pelatihan cara pembuatan dan penyajian minuman campuran bagi masyarakat di Desa Kedonganan. Peserta kegiatan berjumlah total 60 orang, terdiri dari perwakilan dari
\end{abstract}


6 Banjar yang ada di Desa Kedonganan. Kegiatan ini dilakukan dengan 3 (tiga) metode, yaitu berupa kegiatan ceramah, diskusi dan praktek langsung. Hasil kegiatan ini terlihat dari antusias para peserta dalam mengikuti mulai dari hari pertama sampai akhir serta peserta memberikan tanggapan yang sangat positif terhadap kegiatan ini. Harapan mereka agar kegiatan serupa dapat dilakukan secara berkesinambungan dengan materi yang berbedabeda

Kata Kunci: tata hidangan, pelayanan prima, minuman campuran

\section{PENDAHULUAN}

Kecamatan Kuta adalah salah satu kecamatan yang berada di Kabupaten Badung, Bali dengan luas $17,52 \mathrm{~km}^{2}$. Wilayah ini memiliki salah satu tempat tujuan pariwisata yang terkenal hingga ke mancanegara yaitu Pantai Kuta. Selain itu, kawasan ini juga penuh dengan berbagai hotel berbintang, restoran, villa, mall, dan sebagainya. Kecamatan Kuta mempunyai 5 kelurahan/desa yang terdiri dari Kedonganan,Tuban, Kuta, Legian dan Seminyak Kelurahan Kedonganan berada di ujung utara Kecamatan Kuta memiliki luas 190,75 Ha, yang terdiri dari 6 Lingkungan, 6 Banjar Adat dan 1 Desa Adat. Desa Adat Kedonganan merupakan sebuah desa pesisir dimana pada sisi kiri dan kanan desa ini adalah laut. Hal ini yang menyebabkan sektor perikanan dan kelautan menjadi ikon Desa Kedonganan. Bahkan, hingga kini Desa Kedonganan menjadi salah satu sentra usaha perikanan dan kelautan terbesar di Bali. Kehadiran Tempat Pelelangan Ikan (TPI) Kedonganan menunjukkan bahwa Desa Kedonganan memang memegang peranan penting dalam bidang perikanan.

Sekitar tahun 2000-an, Desa Kedonganan mulai terjamah perkembangan kepariwisataan. Berkembangnya pariwisata di Desa Kedonganan tidak bisa dipisahkan dari perkembangan kepariwisataan di daerah Jimbaran. Dengan banyaknya wisatawan yang datang ke Pantai Jimbaran, beberapa penduduk lokal mulai mendirikan warung-warung ikan bakar bagi wisatawan sambil menikmati pemandangan sunset. Kesuksesan warung-warung ikan bakar di Jimbaran, mendorong beberapa warga Desa Kedonganan ikut mendirikan usaha yang sama. Warung-warung tersebut akhirnya berkembang menjadi cafe yang dikemas dengan produk yang berbeda seperti yang ditawarkan oleh cafe yang ada di Jimbaran.

Pada tahun 2007, Desa Kedonganan yang didukung Pemkab Badung menata kawasan Pantai Kedonganan sebagai bagian palemahan desa. Keberadaan cafe ditata agar lebih mampu memaksimalkan potensi warga. Setelah melalui proses yang panjang, berdirilah 24 cafe. Pengelolaan keduapuluh empat cafe ini ini diserahkan kepada enam Banjar Adat yang ada di Desa Adat Kedonganan yaitu Banjar Kubu Alit, Banjar Anyar Gede, Banjar Ketapang, Banjar Pengenderan, Banjar Pasek, dan Banjar Kertayasa. Pengelolaan pantai Kedonganan sebagai objek wisata kuliner berbasis masyarakat ini dijiwai oleh filosofi Tri Hita Karana, karena dengan demikian hubungan masyarakat dengan wisatawan, antar masyarakat dan lingkungan dapat terjalin secara harmonis dan berkelanjutan (Sucipta dan Solihin, 2013). Sejak saat itulah, Pantai Kedonganan dikenal sebagai desa wisata kuliner. Menu kuliner yang ditawarkan yakni ikan bakar, lobster, udang, kerang, kepiting, cumi, serta menu pendukung seperti sambal ala Kedonganan, plecing kangkung, dan 
lainnya. Rasa dan aroma yang ditawarkan di cafe di kawasan Pantai Kedonganan memiliki ciri khas tersendiri yang tidak dimiliki daerah lain.

Pantai Kedonganan kini telah berubah menjadi objek wisata yang sangat menarik. Pemandangan lautnya tak kalah menawan dengan objek wisata pantai lainnya. Terlebih lagi saat malam tiba, kerlip lampu pesawat terbang yang tengah landing di landasan pacu Bandara Ngurah Rai Tuban menambah daya tarik Pantai Kedonganan. Saat ini wisatawan juga dapat menyisir pesisir pantai Kedonganan dengan menunggang Kuda (horse riding). Nama Kedonganan pun mulai disebutsebut di dunia pariwisata. Berbagai biro perjalanan pun mulai memasarkan Pantai Kedonganan. Berdasarkan potensi yang dimiliki oleh Desa Kedonganan, maka mulai muncul ide program wisata baru untuk menambah daya tarik wisata Desa Kedonganan. Selama ini potensi wisata yang sudah dikembangkan baru sebatas daerah pesisir pantai dari Desa Kedonganan, dari sisi perairan belum dikembangkan secara maksimal. Saat ini sudah ada beberapa kegiatan wisata yang dilakukan di perairan Desa Kedonganan yaitu berlayar dengan perahu nelayan tradisional untuk menikmati sunset. Namun kegiatan ini belum bisa dilakukan dalam jumlah yang banyak mengingat satu perahu tradisional hanya mampu memuat 2-3 orang wisatawan.

Berdasarkan informasi dari pihak Tokoh Adat Desa Kedonganan bahwa program wisata yang mulai dirancang antara lain program Sunset Tour dan Romantic Dinner. Tujuan dari program ini adalah untuk meningkatkan pemanfaatan perairan yang dimiliki oleh Desa Kedonganan dengan menggunakan sumber daya yang ada. Program sunset tourdirancang dengan melakukan kerjasama dengan pihak investor pemilik kapal Marina Srikandi 15, dimana pihak Desa Kedonganan ditugaskan untuk menyediakan sumber daya manusia khususnya yang akan memberikan pelayanan selama wisatawan melakukan sunset tour di atas kapal. Pada rancangannya, program sunset tour ini akan menyediakan welcome drink dan minuman cocktail bagi wisatawan yang membeli paket tour ini. Welcome drink adalah minuman yang disajikan untuk tamu yang baru saja datang untuk check in (kamustraveller.com). Pada paket tour ini wisatawan akan diberikan sebatas minuman sebagai peneman selama perjalanan yang menghabiskan waktu kira kira 1,5 sampai 2 jam untuk melihat sunset. Kegiatan ini akan diakhiri dengan makan malam (dinner|) di cafe yang ada di pesisir pantai Kedonganan. Kegiatan wisata ini memang dirancang sedemikian rupa agar semua usaha yang ada di Desa Kedonganan saling terintegrasi.

Melihat peluang kedepan yang ditawarkan oleh pihak investor, maka pihak Desa Kedonganan merasa perlu untuk mempersiapkan sumber daya manusia yang dimilikinya untuk dapat menyediakan produk penunjang program ini yaitu pelayanan minuman, baik minuman alkohol maupun non alkohol. Selain itu dalam menjalankan program secara terintegrasi, dipandang perlu untuk melatih SDM mereka untuk memiliki pengetahuan di bidang pelayanan makanan dan minuman, serta pemahaman mengenai hygiene, sanitasi dan keselamatan kerja. Menyikapi hal tersebut diatas, maka sangat dibutuhkan adanya pelatihan mengenai pelayanan prima, hygiene, sanitasi dan keselamatan kerja serta pembuatan minuman campuran bagi masyarakat di Desa Kedonganan untuk dapat menambah rasa percaya diri karyawan dalam memberikan pelayanan dan untuk mempersiapkan 
SDM yang ada untuk mensukseskan rancangan pengembangan program wisata yang akan dikembangakan di Desa Kedonganan.

Tujuan dari kegiatan ini adalah untuk memberikan gambaran umum mengenai bidang hospitaliti dan pelayanan prima (service excellent) kepada masyarakat di Desa Kedonganan, untuk memberikan pemahaman mengenai hygiene, sanitasi dan keselamatan kerja serta pengetahuan dasar minuman kepada masyarakat di Desa Kedonganan, serta untuk memberikan pelatihan cara pembuatan dan penyajian minuman campuran bagi masyarakat di Desa Kedonganan. Sedangkan sasaran dari kegiatan ini adalah terlaksananya kegiatan pengabdian kepada masyarakat yang berkesinambungan pada bidang hospitaliti dan pelayanan prima, tercapainya pemahaman dan pengetahuan masyarakat mengenai hygiene, sanitasi dan keselamatan kerja serta pengetahuan dasar minuman, dan terwujudnya kemampuan peserta pelatihan untuk mempraktekkan cara pembuatan dan penyajian minuman campuran. Pelaksanaan kegiatan ini merupakan salah satu bentuk implementasi dari Tri Dharma Perguruan Tinggi yang diharapkan dapat memberikan manfaat bagi kehidupan masyarakat. Setelah program pengabdian masyarakat ini dilaksanakan dengan baik dan lancar, para peserta pelatihan mendapatkan sesuatu ilmu baru yang dapat dijadikan bekal dalam kehidupannya.

\section{METODE PELAKSANAAN KEGIATAN}

Kegiatan ini dilakukan dengan 3 (tiga) metode, yaitu berupa kegiatan ceramah, diskusi dan praktek langsung yang dilakukan oleh dosen - dosen Program Studi Manajemen Tata Hidangan (MTH) dengan para peserta kegiatan. Dimana peserta kegiatan berjumlah total 60 orang, terdiri dari perwakilan dari 6 Banjar yang ada di Desa Kedonganan. Kegiatan ini dilaksanakan di Kantor Badan Pengelola Kawasan Pariwisata Pantai Kedonganan (BP-KP2K) yang beralamat di Jalan Pantai Kedonganan.

Setelah kegiatan ini terlaksana terdapat 8 indikator yang dijadikan penilaian terhadap keberhasilan kegiatan ini antara lain : topik pelatihan, materi pelatihan, pemaparan materi pelatihan, media pelatihan, kesesuaian materi dengan aplikasi di tempat kerja, tempat pelatihan, waktu pelatihan serta makanan dan minuman yang disediakan selama pelatihan. Dimana teknik pengumpulan data melalui penyebaran kuesioner kepada semua peserta pelatihan dan kemudian dianalisis menggunakan skala likert.

\section{HASIL DAN PEMBAHASAN}

Kegiatan hari pertama dilakukan dengan metode ceramah dan diskusi. Dimana materi pertama pada sesi ceramah ini adalah materi mengenai potensi dan program yang akan dikembangkan di Desa Kedonganan. Materi ini sangat menarik disampaikan untuk merangsang anak-anak muda yang ada di Desa Kedonganan untuk lebih peduli dan mau membangun desanya kearah yang lebih baik. Selanjutnya adalah materi pengetahuan dasar minuman, materi ini berguna untuk menambah wawasan peserta pelatihan khususnya generasi muda mengenai minuman yang mengandung alkohol. Penyampaian materi ini bertujuan untuk meminimalisasi pengkonsumsian minuman beralkohol yang tidak bertanggung jawab, selain untuk menambah wawasan peserta pelatihan mengenai jenis-jenis 
minuman alkohol. Masyarakat antusias untuk menanyakan beberapa hal seperti batasan umur untuk mengkonsumsi minuman beralkohol, teknik mencampur minuman beralkohol, dan beberapa pertanyaan yang terkait pengetahuan dasar minuman. Materi selanjutnya adalah materi pelayanan prima (Service Excelence). Menurut Rangkuti (2017) pelayanan prima adalah memberikan pelayanan yang dapat memenuhi harapan dan kebutuhan pelanggan, sedangkan menurut Herlambang (2018) pelayanan prima adalah salah satu usaha yang dilakukan organisasi dalam rangka melayani pelanggan dengan sebaik-baiknya sehingga dapat memberikan kepuasan kepada pelanggan. Pada sesi ini terdapat beberapa pertanyaan dari peserta yang menanyakan mengenai beberapa tips untuk mendatangkan tamu lebih dari 1 kali ke restoran. Pertanyaan ini dijawab oleh narasumber bahwa jaman sekarang sudah tidak jamannya tamu yang sama datang ke tempat yang sama berulang kali, tetapi sudah jamannya bagaimana tamu tersebut membagikan pengalaman mereka selama makan di restoran kepada teman-teman lainnya. Caranya adalah dengan memberikan pelayanan yang prima kepada tamu tersebut baik dari segi pelayanan makanan dan minuman maupun dari segi fasilitas. Materi terakhir pada hari pertama pelatihan ini adalah materi mengenai Hygiene, Sanitasi dan Keselamatan Kerja. Menurut Sihite (2000:3) menyatakan hygiene adalah bagaimana caranya orang memelihara dan melindungi kesehatan. Sedangkan pengertian sanitasi menurut Rocket (2017) merupakan upaya yang dilakukan demi menjamin dan mewujudkan kondisi yang sudah memenuhi syarat kesehatan. Bangun (2012:377) mengemukakan bahwa keselamatan kerja adalah perlindungan atas keamanan kerja yang dialami pekerja baik fisik maupun mental dalam lingkungan pekerjaan. Kegiatan pelatihan pada hari pertama dapat dilihat pada Gambar 1 berikut ini.

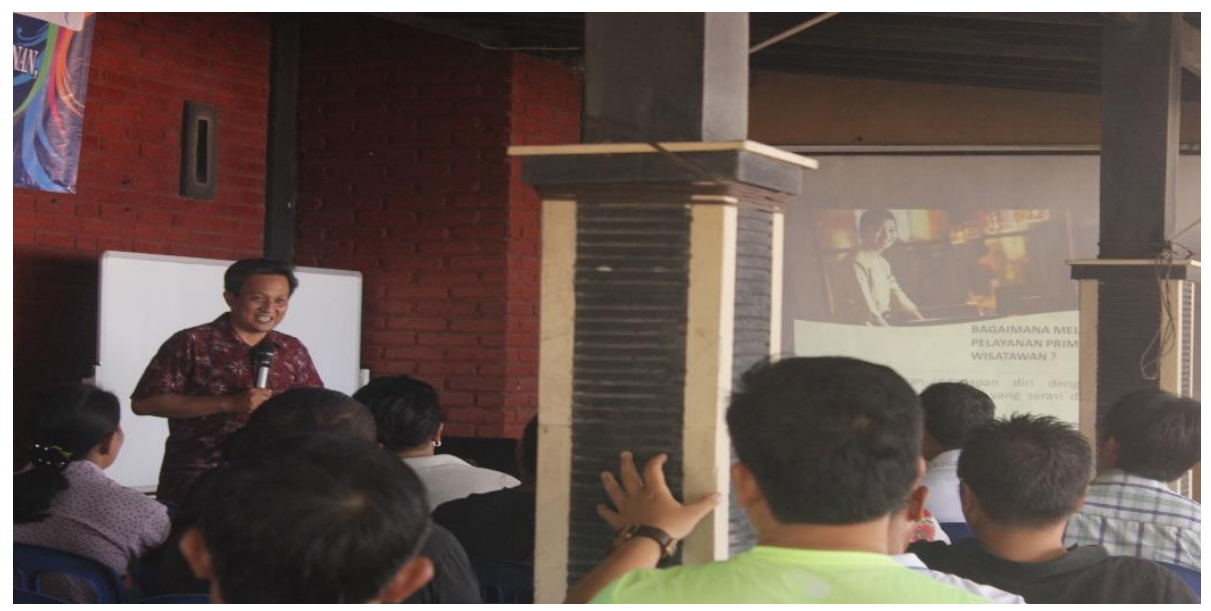

Gambar 1

Pemaparan Materi Pelatihan Oleh Narasumber

Pelatihan hari kedua dilanjutkan dengan kegiatan demontrasi dan praktek pembuatan minuman campuran. Menurut Atmodjo (2004:35) minuman campuran ialah minuman hasil campuran dua jenis minuman atau lebih yang terdiri dari satu bagian atau lebih minuman berkadar alkohol dengan bahan lain yang tidak mengandung alkohol dalam perbandingan bebas. Para narasumber 
mendemonstrasikan cara pembuatan minuman campuran welcome drink dan cocktail, sekaligus memberikan kesempatan kepada peserta pelatihan untuk mencicipi minuman tersebut. Setelah diberikan demonstrasi cara membuat minuman campuran welcome drink dan cocktail, seluruh peserta dipersilahkan untuk mempraktekkan langsung cara membuat minuman tersebut dengan dipandu oleh narasumber. Seluruh peserta tampak sangat antusias mengikuti sesi praktek ini karena kegiatan ini sangat menarik dan interaktif. Beberapa diantaranya antusias mendokumentasikan kegiatan ini dalam bentuk foto dan video. Peserta pelatihan diberikan taster minuman berupa juice, sandy, dan mocktail untuk mengantisipasi cuaca yang sangat panas disekitar tempat pelatihan. Para peserta pelatihan tampak sangat antusias dalam mengikuti kegiatan tersebut. Hal tersebut dapat dilihat pad Gambar 2 berikut ini.

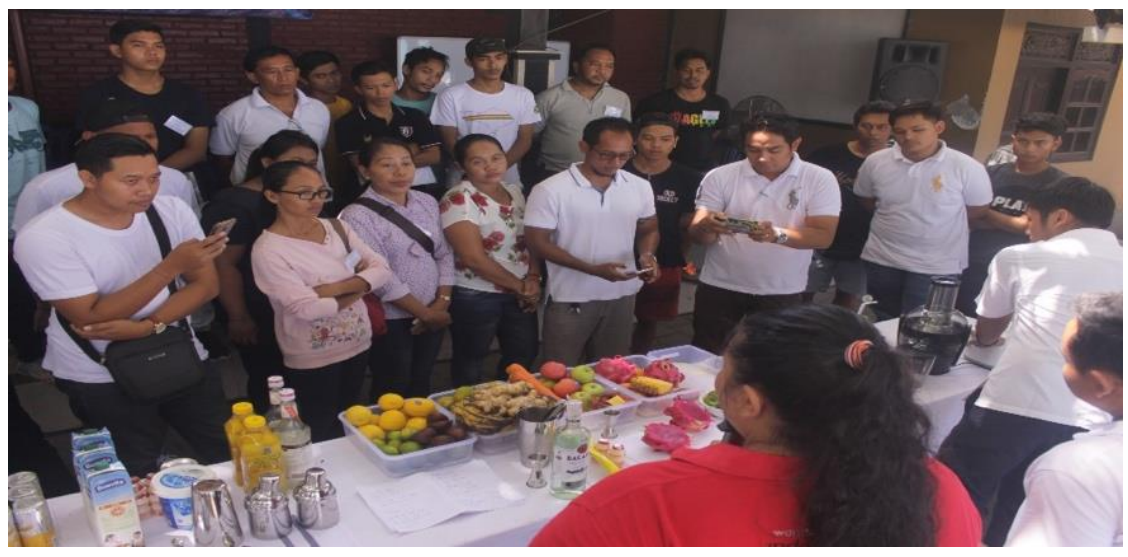

Gambar 2

Demontrasi Pembuatan Minuman Campuran Oleh Narasumber

Untuk meningkatkan kualitas kegiatan di masa yang akan datang, disebarkan kuesioner kepada seluruh peserta di akhir kegiatan, dimana hasilnya dapat dilihat pada Tabel 1 dibawah ini:

\begin{tabular}{clrrrrc}
\hline NO & \multicolumn{1}{c}{ INDIKATOR } & $\begin{array}{c}\text { SGT. } \\
\text { BAIK }\end{array}$ & BAIK & KURANG & $\begin{array}{c}\text { SGT. } \\
\text { KURANG }\end{array}$ & $\begin{array}{c}\text { TOTAL } \\
\text { (Org) }\end{array}$ \\
\hline 1 & Topik Pelatihan & 29 & 31 & 0 & 0 & 60 \\
2 & $\begin{array}{l}\text { Materi Pelatihan (hand } \\
\text { out) }\end{array}$ & 22 & 38 & 0 & 0 & 60 \\
3 & $\begin{array}{l}\text { Pemaparan/penyampaia } \\
\text { n materi Pelatihan }\end{array}$ & 33 & 27 & 0 & 0 & 60 \\
4 & Media Pelatihan & 18 & 42 & 0 & 0 & 60 \\
5 & $\begin{array}{l}\text { Kesesuaian materi dengan } \\
\text { aplikasi di tempat kerja }\end{array}$ & 19 & 41 & 0 & 0 & 60 \\
\hline
\end{tabular}


Ni Kadek Eni Juniari, Putu Mira Astuti Pranadewi

\begin{tabular}{lllllll}
\hline 6 & Tempat Pelatihan & 20 & 35 & 5 & 0 & 60 \\
7 & Waktu Pelatihan & 18 & 38 & 4 & 0 & 60 \\
8 & Makanan dan minuman & 28 & 32 & 0 & 0 & 60 \\
\hline
\end{tabular}

Tabel 1

Rekapitulasi Hasil Kuesioner Peserta berdasarkan Jumlah Sumber: kuesioner (data diolah)

Berdasarkan data pada Tabel 1 diatas dapat dilihat bahwa sebagian besar peserta pelatihan memberikan penilaian sangat baik dan baik dan hanya beberapa orang peserta yang memberikan penilaian kurang pada indikator tempat latihan dan waktu pelatihan. Walaupun hanya sedikit peserta yang memberikan penilaian kurang pada beberapa indikator tersebut, hal ini perlu mendapat perhatian serius dari panitia untuk pelaksanaan kegiatan serupa kedepannya. Penilaian kurang pada indikator tempat pelaksanaan di sebabkan tempat pelatihan dekat dengan pantai yang menyebabkan suhu di tempat pelatihan agak panas. Panitia sudah mengantisipasi dengan menyediakan beberapa kipas angin, namun hal ini belum cukup meredakan suhu di tempat pelatihan. Sedangkan untuk indikator waktu pelatihan dinilai kurang mengingat pelatihan ini hanya dilakukan selama 2 hari, dianggap belum cukup bagi para peserta untuk melatih kemampuan mereka untuk mengetahui lebih banyak mengenai pembuatan dan penyajian minuman.

Untuk melihat tingkat penilaian peserta terhadap delapan indikator pelatihan dapat dilihat pada Tabel 2 dengan penilaian empat skor nilai, yaitu: sangat baik (skor 4), baik (skor 3), kurang (skor 2), dan sangat kurang (skor 1). Pada skor tiap pertanyaan dihitung dengan mengalikan seluruh frekwensi data dengan skor nilai, total hasil perkalian tersebut dijumlahkan dengan dibagi dengan jumlah responden, skor yang didapat diklasifikasikan menurut interval kelas dengan oerhitingan sebagai berikut:

1. Jumlah kelas : 4

2. Range $=$ nilai tertinggi - nilai terendah

$$
\text { 4-1 = } 3
$$

3. Interval kelas dihiting dengan rumus :

$$
\mathrm{K} 4^{\mathrm{C}=\underline{\mathrm{R}}=\underline{3}=0,75}
$$

Keterangan :

$\mathrm{C}=$ Interval kelas

$\mathrm{R}=$ Range

$\mathrm{K}=$ Jumlah klasifikasi

Interval kelasnya adalah sebagai berikut :

1.00 sampai - $<1,80$ : sangat kurang

1.80 sampai $-<2.60$ : kurang

2.60 sampai $-<3.40$ : baik

3.40 sampai $-<4.20$ : sangat baik 
Ni Kadek Eni Juniari, Putu Mira Astuti Pranadewi

Berikut Tabel 2 yang menunjukkan tingkat penilaian peserta pelatihan terhadap PkM prodi MTH di Desa Kedonganan

Tabel 2

Tabel Tingkat Penilaian Peserta

\begin{tabular}{|c|c|c|c|}
\hline NO & INDIKATOR & Nilai & $\begin{array}{l}\text { Tingkat } \\
\text { penilaian }\end{array}$ \\
\hline 1 & Topik Pelatihan & 3.48 & $\begin{array}{l}\text { Sangat } \\
\text { Baik }\end{array}$ \\
\hline 2 & Materi Pelatihan (hand out) & 3.36 & Baik \\
\hline 3 & $\begin{array}{l}\text { Pemaparan / penyampaian } \\
\text { materi Pelatihan }\end{array}$ & 3.55 & $\begin{array}{l}\text { Sangat } \\
\text { Baik }\end{array}$ \\
\hline 4 & Media Pelatihan & 3.30 & Baik \\
\hline 5 & $\begin{array}{l}\text { Kesesuaian materi dengan } \\
\text { aplikasi di tempat kerja }\end{array}$ & 3.32 & Baik \\
\hline 6 & Tempat Pelatihan & 3.25 & Baik \\
\hline 7 & Waktu Pelatihan & 3.23 & Baik \\
\hline \multirow[t]{2}{*}{8} & Makanan dan minuman & 3.46 & Baik \\
\hline & Penilaian secara keseluruha & 3,37 & Baik \\
\hline
\end{tabular}

\section{Sumber : kuesioner (data diolah)}

Merujuk data pada Tabel 2 diatas, dapat dilihat bahwa peserta pelatihan yang berjumlah 60 orang menilai bahwa kegiatan ini berada pada kategori baik dengan skor nilai 3.37 dari delapan indikator yang diberikan. Penilaian indikator pemaparan /penyampaian materi pelatihan mendapatkan skor tertinggi yaitu 3.55.

Begitu pula dengan indikator topik pelatihan mendapat penilaian dengan kategori sangat baik. Hal ini menunjukkan bahwa peserta pelatihan sangat tertarik dengan metode pelatihan yang dilakukan yaitu praktek. Untuk topik pelatihan yang disampaikan sudah sesuai dengan kebutuhan masyarakat di Desa Kedonganan. Diantara 8 indikator yang ada pada kuesioner, yang mendapatkan skor terendah adalah indikator waktu pelatihan dan tempat pelatihan (masih dalam kategori baik). Hal ini terjadi karena lokasi pelatihan berada di ruangan terbuka di pinggir pantai, sehingga cuaca terasa sangat panas, walaupun panitia sudah menyiapkan standing cooler fan. Hal ini menunjukkan bahwa tempat pelatihan walaupun sudah dalam skor baik masih perlu ditingkatkan lagi kedepannya.

\section{KESIMPULAN}

Pelatihan bidang tata hidangan terkait teknik pelayanan makanan dan minuman serta teknik pembuatan minuman campuran sangat dirasakan manfaatnya oleh masyarakat Desa Adat Kedonganan. Upaya yang dilakukan melalui ceramah, diskusi dan praktek langsung pembuatan minuman campuran dapat menggugah dan mendorong masyarakat untuk lebih kreatif dalam membuat minuman campuran. Melalui kegiatan ini peserta pelatihan mendapatkan sesuatu ilmu baru yang dapat dijadikan bekal dalam kehidupannya khususnya terkait pemberian layanan makanan dan minuman kepada wisatawan. Hasil kegiatan pengabdian kepada 
Ni Kadek Eni Juniari, Putu Mira Astuti Pranadewi

masyarakat ini diharapkan dapat terus berlanjut dengan dibuatkan rencana pelatihan yang lebih lama dan berjenjang sehingga peserta pelatihan dapat meningkatkan keterampilan dan pengetahuan mereka.

\section{PERNYATAAN PENGHARGAAN}

Pada kesempatan ini ucapan terima kasih dan penghargaan disampaikan kepada narasumber yaitu Bendesa Adat Desa Kedonganan yang telah memberikan informasi serta kesempatan untuk membagi pengalaman dan ilmu kepada masayarakatnya. Serta tidak lupa diucapkan penghargaan yang setinggi-tingginya kepada pimpinan Poltekpar Bali yang telah mendukung kegiatan pengabdian kepada masyarakat baik secara material maupun secara administrasi, sehingga kegiatan ini dapat terselesaikan dengan baik

\section{DAFTAR PUSTAKA}

Atmodjo. M W. 2004. Bar, Minuman dan Pelayanan. Yogyakarta: Andi

Bangun, Wilson. 2012. Manajemen Sumber Daya Manusia. Jakarta: Erlangga

Herlambang, S. .2018. Customer Service Rumah Sakit dan Jasa Kesehatan. Yogyakarta: Gosyen Publishing

Rangkuti, Freddy. 2017. Customer Care Excellence: Meningkatkan Kinerja Perusahaan Melalui Pelayanan Prima Plus Analisis Kasus Jasa Raharja. Jakarta. Gramedia Pustaka Utama

Sihite, Richard. 2000. Food Product (Dasar-DasarTata Boga). Surabaya: Penerbit SIC

Sucipta. Made Abdi, Solihin. 2013. Pengelolaan Pantai Kedonganan Sebagai Daya Tarik Wisata Kuliner Berbasis Masyarakat di Desa Kedonganan. Soshum Jurnal Sosial dan Humaniora, VOL. 3, NO.1

Anonim. Kamustraveller.com. Diakses pada hari Selasa, 12 Maret 2019, pukul 10.00 Wita

Rocket. 2017. Pengertian Sanitasi, Ruang Lingkup, Tujuan Beserta Manfaatnya. Retrieved Maret 10, 2018, from http://rocketmanajemen.com/definisisanitasi/ 